\title{
The relationship between green roofs and the thermal environment in Taipei city
}

\author{
C.-Y. Sun \\ Department of Land Economics, National Chengchi University, Taiwan
}

\begin{abstract}
During the last decade, a large amount of research has been published in Taiwan on different strategies for the reduction of the urban heat island effect. The most important strategy for reducing ambient temperature and mitigating the heat island effect is encouraging citizens to build a green roof on their own buildings. In order to analyze the effect of green roofs on the thermal environment, this paper collects temperature and humidity data from two buildings with different roof greening levels and tries to analyze the relationship between roof greening and the thermal environment in Taipei city. The result of this research can give citizens an idea what kind of thermal environment they can get if they make some greening on their roofs; moreover, it also can provide some useful data to governments for calculating the environmental benefit if they carry out the green roof policy.
\end{abstract}

Keywords: heat island effect, green roof, greening level.

\section{Introduction}

Taipei is the biggest metropolis of Taiwan, which has around 5,000,000 citizens with a very high living density. The high concentration of buildings in the city has resulted in many environmental issues, such as air pollution, traffic jams, urban warming and the urban heat island effect. In order to solve these problems, several studies indicated that green roofs can be used to mitigate some problems associated with storm water runoff, the urban heat island effect, wildlife habitat, air quality and energy consumption (Liu and Baskaran [1]; Wong et al. [2]; Takebayashi and Moriyama [4]). In recent years, due to ecological concerns, the government has promoted the building of sustainable architecture to mitigate the building's negative impact on the urban environment and to create harmony 
between humans in general and the inhabitants living in the urban area. Therefore, making more green roofs in the city could be the best ecological solution. Green roofs can improve air quality, mitigate the heat island effect, beautify the environment, and make the city more sustainable simultaneously.

Although green roofs can cool the ambient air through consuming solar heat gain for transpiration and photosynthesis, some quantitative data on their thermal benefits are desirable for exploring the thermal impacts of green roofs in the Taipei metropolitan area. The objective of this study is to find the answers for the reduction of air temperatures in four different level heights using two types green roofs.

\section{Method}

\subsection{Study area}

The two study areas are located in Taipei city. Site A is the roof of one international company with an abundance of vegetation. Site B is the roof of an elementary school building with a large grass area. Both sites have green roofs covered by different vegetations (Figs. 1 and 2).
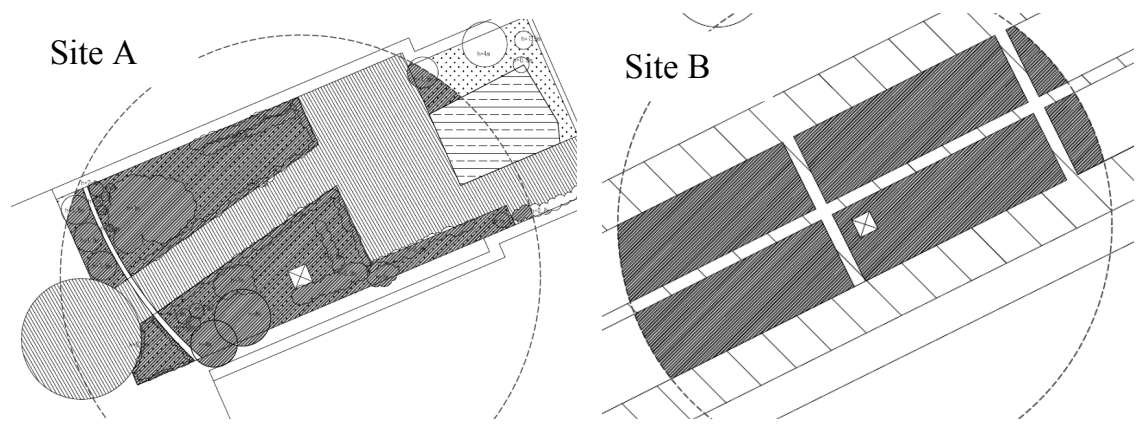

Figure 1: $\quad$ The map of the study areas (Site A and Site B).
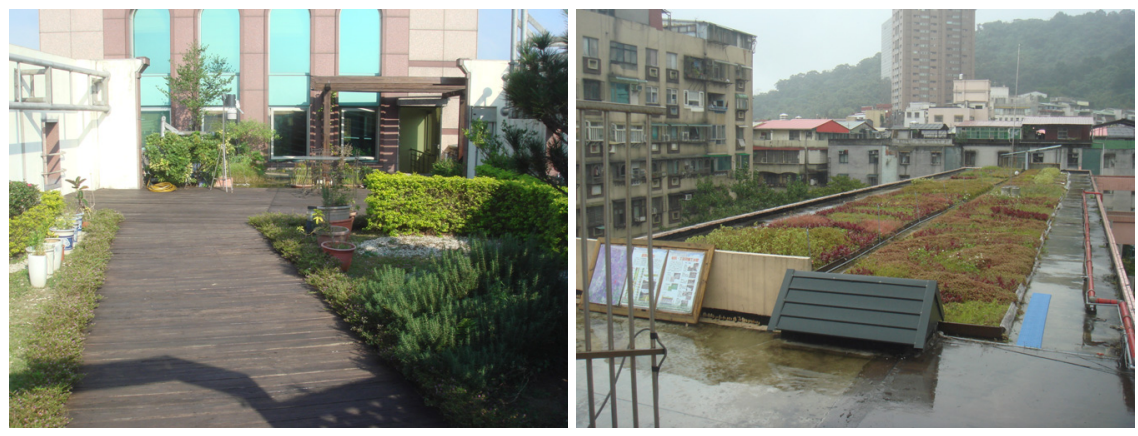

Figure 2: $\quad$ Pictures of Site A (left) and Site B (right). 


\subsection{Measurements}

We installed the temperature measurements at four different level heights $(0.5$, 2.5, 4.5, and 6.5 meter height) on the green roofs $(\mathrm{G})$ of both Site A and Site B in order to monitor the temperature influence of vegetation on the roofs. We also installed the comparators on non-green roofs (NG) near Site A and Site B to collate data for making comparison analyses.

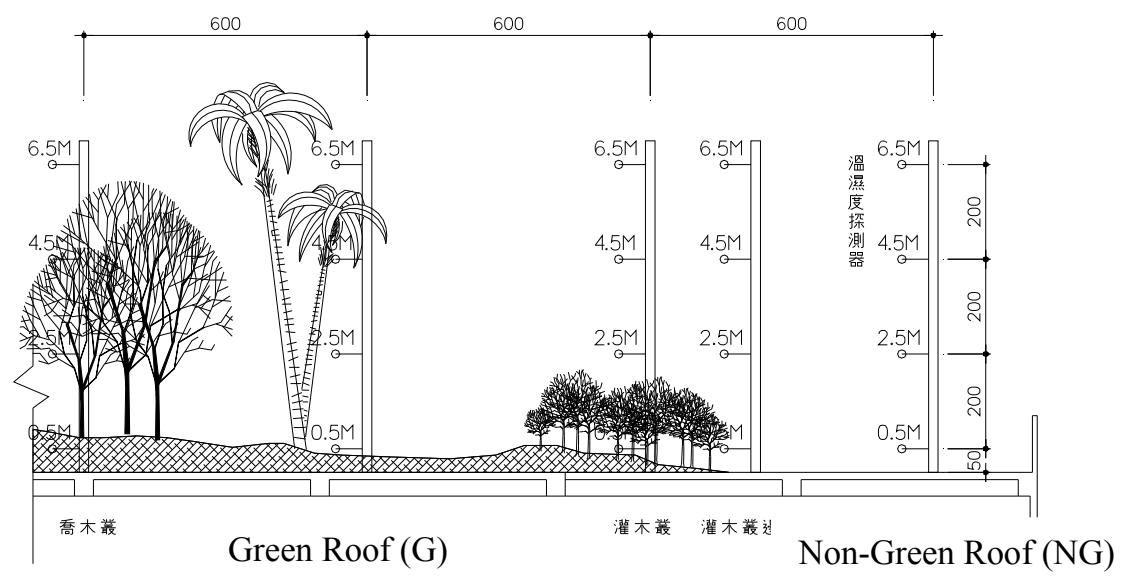

Figure 3: The instrument setting on the green roof and non-green roof in this study for comparison analyses.

\subsection{Data analysis}

In this research, the green coverage ratio of Site A and Site B are $24.42 \%$ and $35.05 \%$ by calculation of the greening area within a 10 meter circle area. We not only made the comparison analyses of the data of four different level heights in the two study sites in order to quantify the thermal benefit of green roofs, but also to try to analyze the relation between the green coverage ratio and air temperature in both sites.

\section{Results}

\subsection{The temperature difference between the greening area and the non-greening area}

The objective of this study is to find the answers for the reduction of air temperatures in four different level heights in two types green roofs. Therefore, we calculated the difference of temperature between the greening area and the non-greening area in both sites. The result showed that the thermal benefit of greening in Site A was 0.438 and in Site B was 0.202 , on average. We also verified that the greening roofs can decrease the ambient air temperature around by 0.320 in winter, on average (Table 1 ). 
Table 1: $\quad$ The temperature difference (degree $\mathrm{C}$ ) between the greening area and the non-greening area at 0.5 meter height in the two study sites on three measuring dates.

\begin{tabular}{|c|c|c|c|c|}
\hline Date & 29 Dec. 2009 & 10 Jan. 2010 & 10 Feb. 2010 & Average \\
\hline Site A & -0.363 & -0.472 & -0.477 & -0.438 \\
\hline Site B & -0.169 & -0.148 & -0.288 & -0.202 \\
\hline Average & -0.266 & -0.310 & -0.382 & -0.320 \\
\hline
\end{tabular}

Table 2: $\quad$ The temperature difference (degree $\mathrm{C}$ ) between the greening area and the non-greening area at four different level heights in Site A on three measuring dates.

\begin{tabular}{|c|c|c|c|c|c|}
\hline Date & Height & $0.5 \mathrm{~m}$ & $2.5 \mathrm{~m}$ & $4.5 \mathrm{~m}$ & $6.5 \mathrm{~m}$ \\
\hline \multirow{3}{*}{$2009 / 12 / 29$} & Greening area & 15.709 & 15.787 & 15.939 & 15.951 \\
\cline { 2 - 6 } & Non-Greening Area & 16.073 & 15.912 & 16.083 & 15.930 \\
\cline { 2 - 6 } & Temp. Difference & -0.363 & -0.125 & -0.145 & 0.022 \\
\hline \multirow{3}{*}{$2010 / 01 / 20$} & Greening area & 18.527 & 18.671 & 18.848 & 18.822 \\
\cline { 2 - 6 } & Non-Greening Area & 18.999 & 18.869 & 18.986 & 18.791 \\
\cline { 2 - 6 } & Temp. Difference & -0.472 & -0.198 & -0.138 & 0.031 \\
\hline \multirow{3}{*}{$2010 / 02 / 20$} & Greening area & 23.449 & 23.515 & 23.613 & 23.621 \\
\cline { 2 - 6 } & Non-Greening Area & 23.926 & 23.714 & 23.738 & 23.519 \\
\cline { 2 - 6 } & Temp. Difference & -0.477 & -0.199 & -0.124 & 0.102 \\
\hline
\end{tabular}

Table 3: $\quad$ The temperature difference (degree $\mathrm{C}$ ) between the greening area and the non-greening area at four different level heights in Site B on three measuring dates.

\begin{tabular}{|c|c|c|c|c|c|}
\hline Date & Height & $0.5 \mathrm{~m}$ & $2.5 \mathrm{~m}$ & $4.5 \mathrm{~m}$ & $6.5 \mathrm{~m}$ \\
\hline \multirow{3}{*}{$2009 / 12 / 29$} & Greening area & 15.640 & 15.601 & 15.672 & 15.644 \\
\cline { 2 - 6 } & Non-Greening Area & 15.809 & 15.816 & 15.702 & 15.640 \\
\cline { 2 - 6 } & Temp. Difference & -0.169 & -0.215 & -0.029 & 0.004 \\
\hline \multirow{3}{*}{$2010 / 01 / 20$} & Greening area & 19.121 & 18.960 & 18.951 & 18.896 \\
\cline { 2 - 6 } & Non-Greening Area & 19.269 & 19.205 & 19.029 & 18.967 \\
\cline { 2 - 6 } & Temp. Difference & -0.148 & -0.245 & -0.079 & -0.071 \\
\hline \multirow{3}{*}{$2010 / 02 / 20$} & Greening area & 23.314 & 23.186 & 23.173 & 23.146 \\
\cline { 2 - 6 } & Non-Greening Area & 23.602 & 23.537 & 23.224 & 23.136 \\
\cline { 2 - 6 } & Temp. Difference & -0.288 & -0.350 & -0.050 & 0.010 \\
\hline
\end{tabular}

\subsection{The temperature difference at four different level heights}

By analyzing the data of two study sites, this research demonstrated that the vegetation of green roofs can influence ambient air temperature at 0.5 and 2.5 meter height above the rooftop (Tables 2 and 3 ). The result also indicated that 
the green roof decreased air temperature at 0.5 meter height significantly in Site $\mathrm{A}$, and can cool the air temperature at 2.5 meter height more conspicuously in Site B because two sites have different greening types and coverage ratios.

\subsection{The relationship between the greening coverage ratio and the air temperature at 0.5 meter height}

By the calculations, the green coverage ratio of Site A and Site B are $24.42 \%$ and $35.05 \%$, respectively. Figures 16 to 21 show that the green area has a lower ambient air temperature than the non-green area based on the day-time average. Comparing the green coverage ratio of the two sites with temperature data, Site A has higher thermal benefit than Site B, even though it has a lower green coverage ratio. This means the most important factor influencing ambient air temperature in green roofs is greening abundance. Therefore, this means that a place must have both a higher green coverage ratio and an abundance of vegetation, then it can have a good performance in a cooling environment and mitigate the urban heat island effect well.

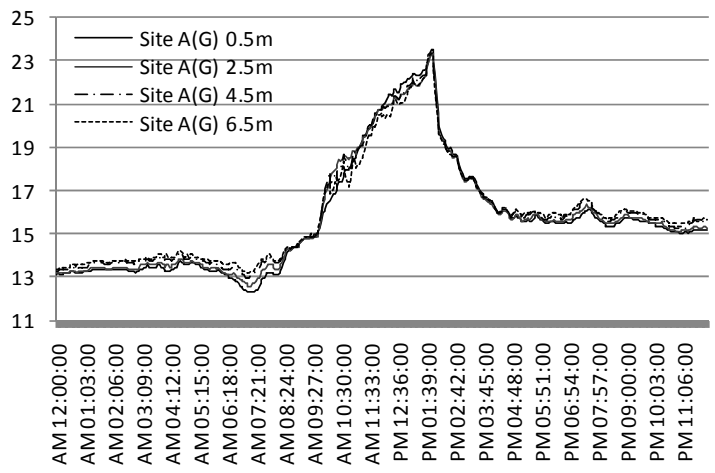

Figure 4: The temperature data at $0.5 \mathrm{~m}, 2.5 \mathrm{~m}, 4.5 \mathrm{~m}$ and $6.5 \mathrm{~m}$ heights in Site A (G) on 29 Dec 2009.

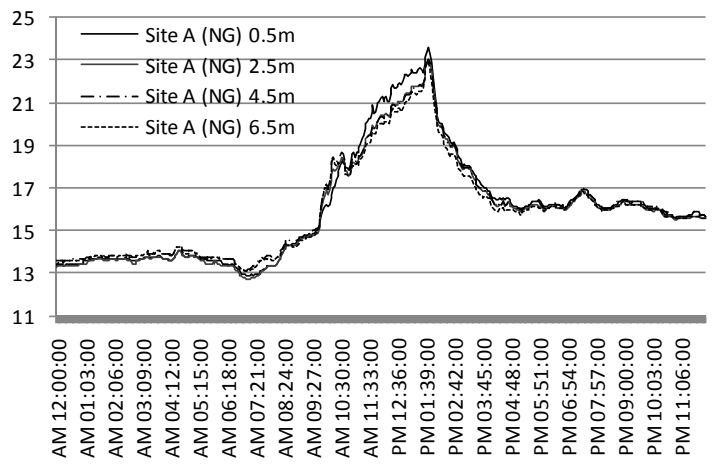

Figure 5: The temperature data at $0.5 \mathrm{~m}, 2.5 \mathrm{~m}, 4.5 \mathrm{~m}$ and $6.5 \mathrm{~m}$ heights in Site A (NG) on 29 Dec 2009. 
82 Design and Nature V

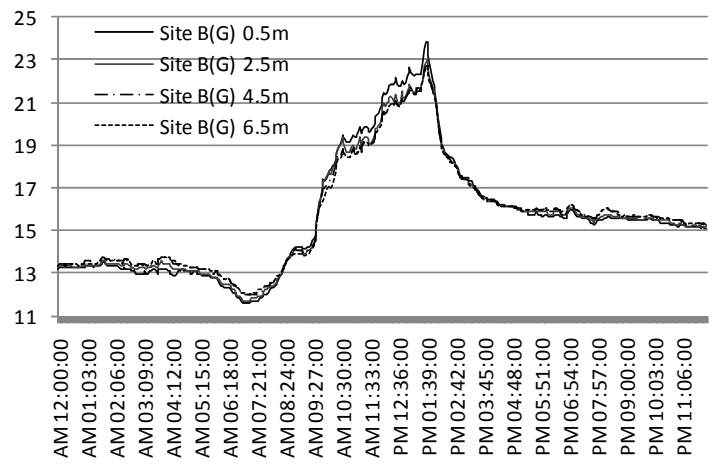

Figure 6: The temperature data at $0.5 \mathrm{~m}, 2.5 \mathrm{~m}, 4.5 \mathrm{~m}$ and $6.5 \mathrm{~m}$ heights in Site B (G) on 29 Dec 2009.

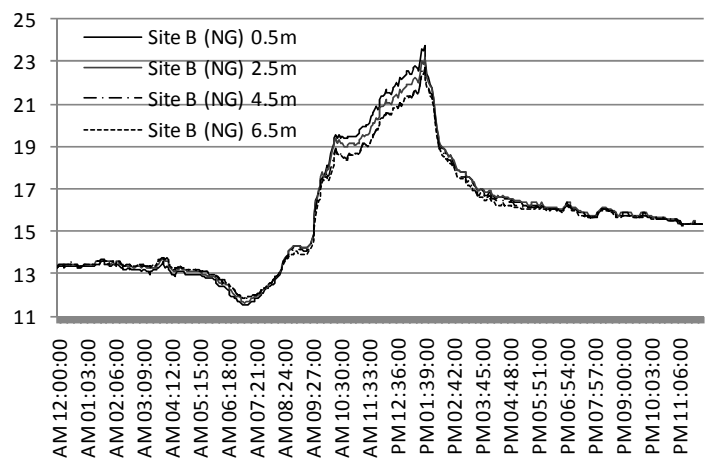

Figure 7: The temperature data at $0.5 \mathrm{~m}, 2.5 \mathrm{~m}, 4.5 \mathrm{~m}$ and $6.5 \mathrm{~m}$ heights in Site B (NG) on 29 Dec 2009.

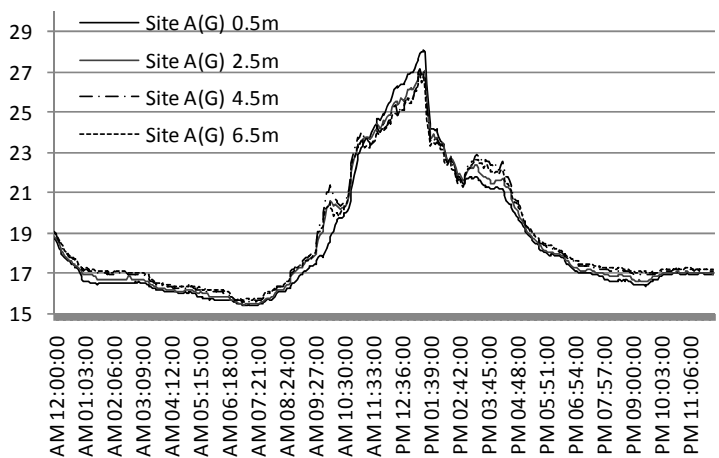

Figure 8: The temperature data at $0.5 \mathrm{~m}, 2.5 \mathrm{~m}, 4.5 \mathrm{~m}$ and $6.5 \mathrm{~m}$ heights in Site A (G) on 10 Jan 2010. 


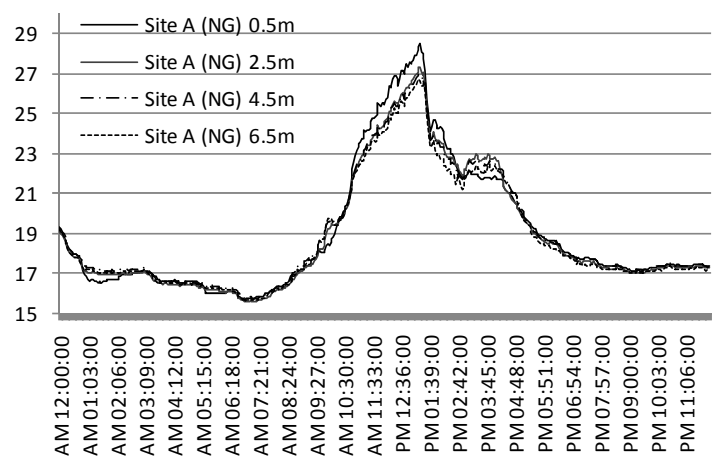

Figure 9: The temperature data at $0.5 \mathrm{~m}, 2.5 \mathrm{~m}, 4.5 \mathrm{~m}$ and $6.5 \mathrm{~m}$ heights in Site A (NG) 10 Jan 2010.

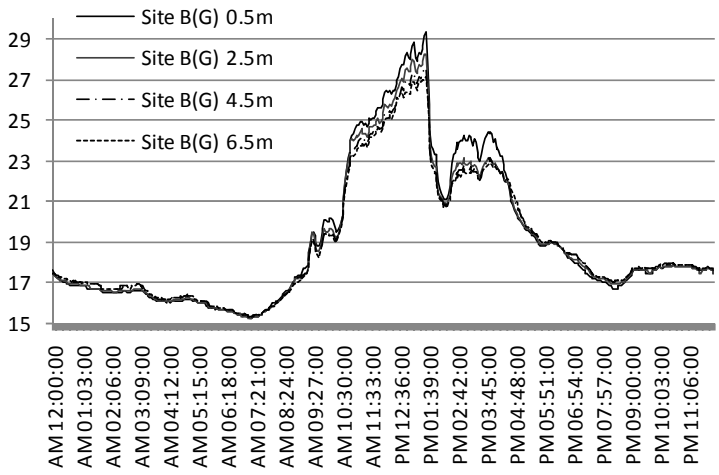

Figure 10: The temperature data at $0.5 \mathrm{~m}, 2.5 \mathrm{~m}, 4.5 \mathrm{~m}$ and $6.5 \mathrm{~m}$ heights in Site B (G) on 10 Jan 2010.

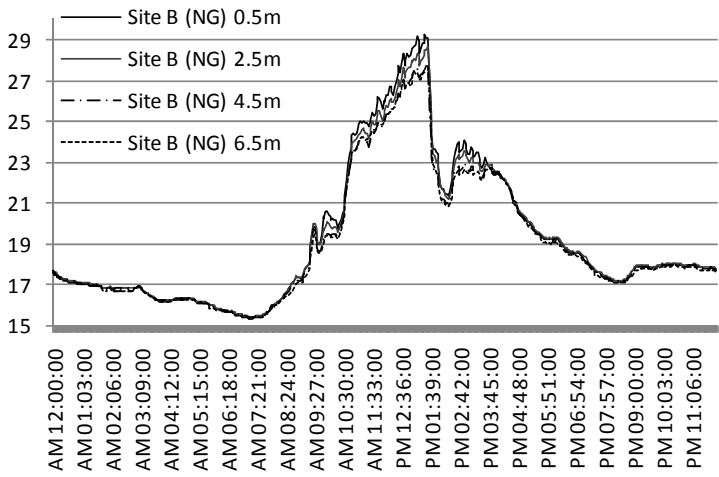

Figure 11: The temperature data at $0.5 \mathrm{~m}, 2.5 \mathrm{~m}, 4.5 \mathrm{~m}$ and $6.5 \mathrm{~m}$ heights in Site $\mathrm{B}(\mathrm{NG})$ on 10 Jan 2010. 
84 Design and Nature V

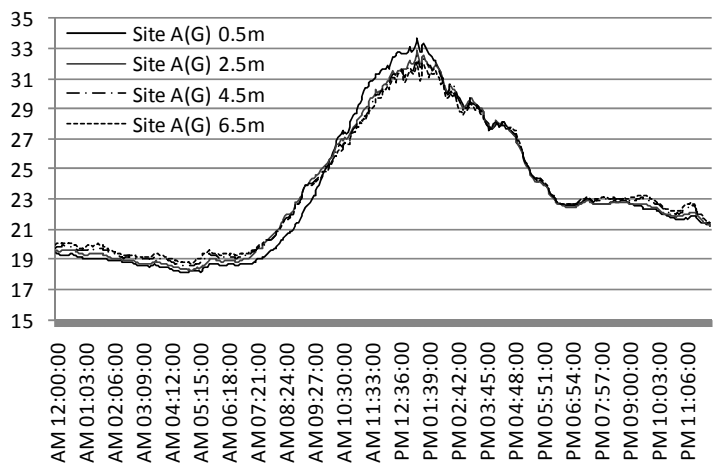

Figure 12: The temperature data at $0.5 \mathrm{~m}, 2.5 \mathrm{~m}, 4.5 \mathrm{~m}$ and $6.5 \mathrm{~m}$ heights in Site A (G) on 10 Feb 2010.

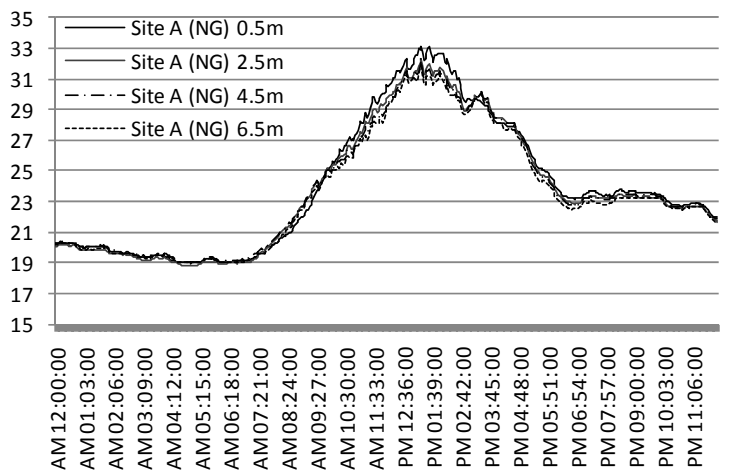

Figure 13: The temperature data at $0.5 \mathrm{~m}, 2.5 \mathrm{~m}, 4.5 \mathrm{~m}$ and $6.5 \mathrm{~m}$ heights in Site A (NG) on 10 Feb 2010.

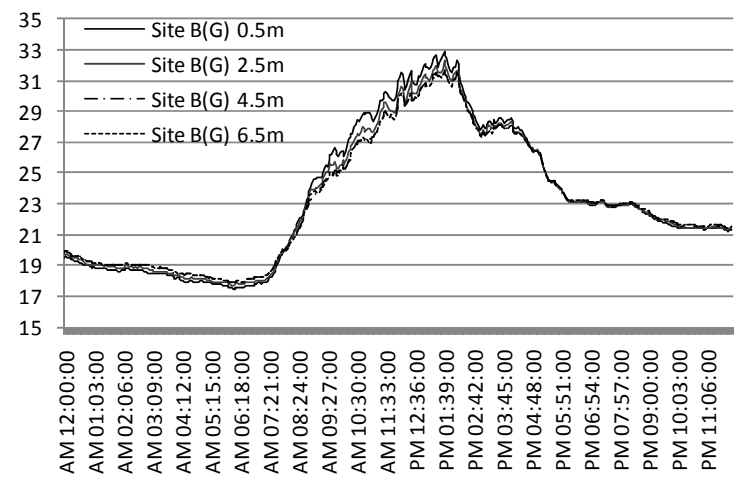

Figure 14: The temperature data at $0.5 \mathrm{~m}, 2.5 \mathrm{~m}, 4.5 \mathrm{~m}$ and $6.5 \mathrm{~m}$ heights in Site B (G) on 10 Feb 2010. 


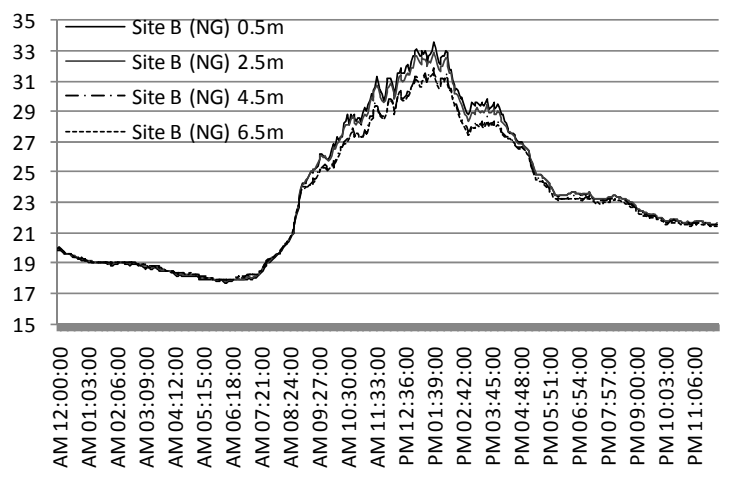

Figure 15: The temperature data at $0.5 \mathrm{~m}, 2.5 \mathrm{~m}, 4.5 \mathrm{~m}$ and $6.5 \mathrm{~m}$ heights in Site B (NG) on 10 Feb 2010.

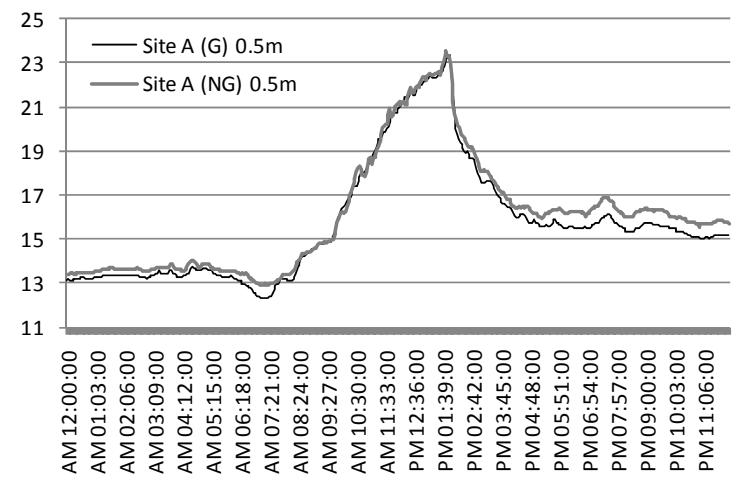

Figure 16: The temperature data at 0.5 meter height in Site A between the greening area $(\mathrm{G})$ and the non-greening area (NG) on 29 Dec 2009.

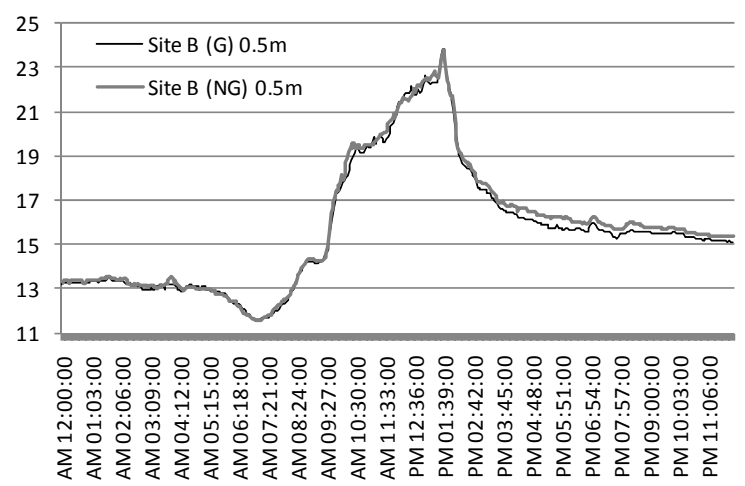

Figure 17: The temperature data at 0.5 meter height in Site $\mathbf{B}$ between the greening area $(\mathrm{G})$ and the non-greening area (NG) on 29 Dec 2009. 
86 Design and Nature V

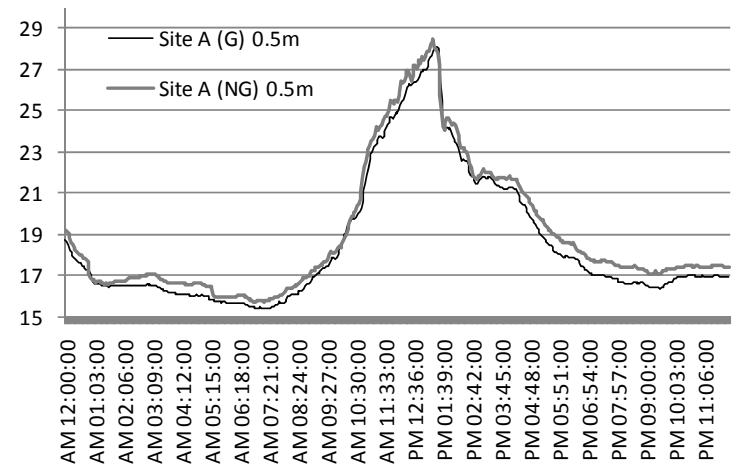

Figure 18: The temperature data at 0.5 meter height in Site A between the greening area $(\mathrm{G})$ and the non-greening area (NG) on 10 Jan 2010.

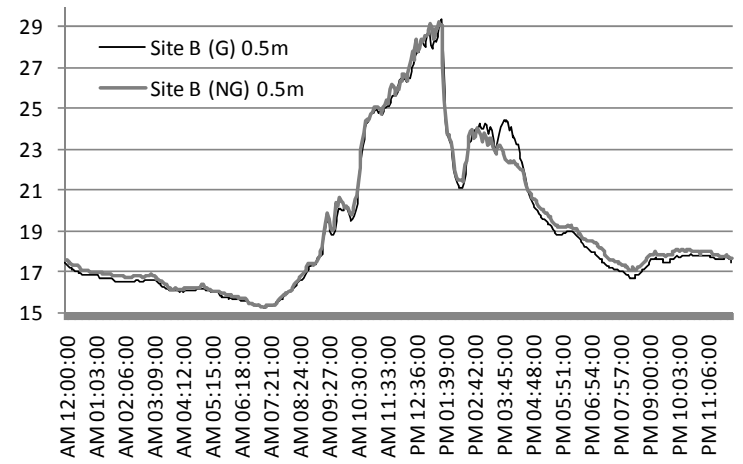

Figure 19: The temperature data at 0.5 meter height in Site B between the greening area $(\mathrm{G})$ and the non-greening area (NG) on 10 Feb 2010.

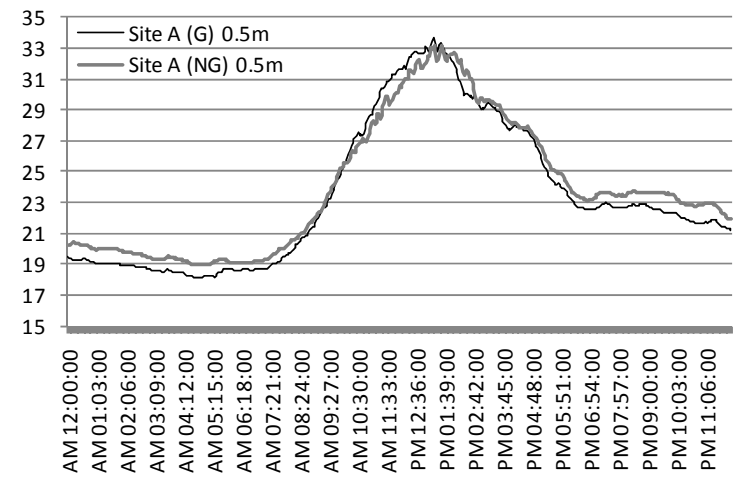

Figure 20: The temperature data at 0.5 meter height in Site A between the greening area $(\mathrm{G})$ and the non-greening area $(\mathrm{NG})$ on 10 Jan 2010. 


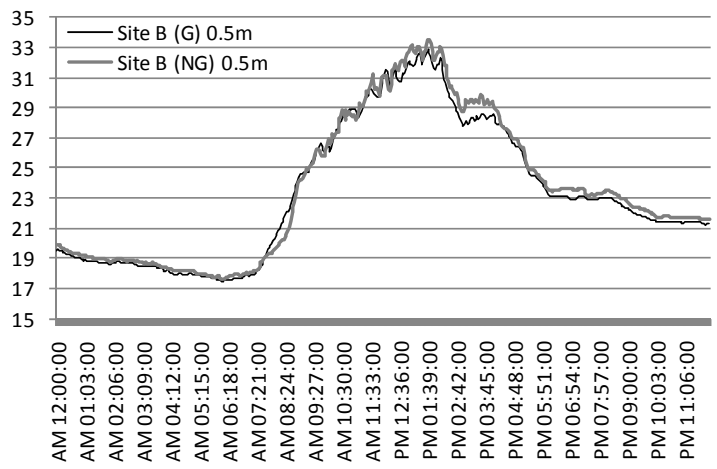

Figure 21: The temperature data at 0.5 meter height in Site B between the greening area $(\mathrm{G})$ and the non-greening area (NG) on 10 Feb 2010.

\section{Conclusions}

In this study, the thermal impacts of green roofs in Taipei city were investigated through field measurements. From this quantitative research, it has been shown that there is an important potential of lowering urban temperatures when the building roof is covered with vegetation. The average thermal benefits of two green roof study sites are 0.438 and 0.320 , respectively. It can be concluded that planting vegetation on the rooftop could not only beautify the environment, but also decrease temperature in the urban area.

Regarding the results of this study, we indicated that green roofs have significant influence on cooling ambient air at 0.5 and 2.5 meter height, and the quality and quantity of the greening roof played important roles in lowering temperature compared with the green coverage ratio. Therefore, if governments intend to use green roofs to mitigate the urban heat island effect, making an Act to stipulate the vegetation abundances for every single building roof would be a very wise and efficient policy.

\section{Acknowledgements}

The support of the National Science Council (project NSC 98-2221-E-004-011 and NSC 98-2218-E-004-001), Republic of China (Taiwan), the Delta Electronics Foundation and the Wu-Sing Elementary School are gratefully acknowledged.

\section{References}

[1] Liu KKY, Baskaran B., 2003, “Thermal performance of green roofs through field evaluation" Proceedings for the first North American green roof infrastructure conference, awards, and trade show, Chicago, IL, May 29-30, 2003, 1-10. 
88 Design and Nature V

[2] Wong NH, Chen Y, Ong CL, Sia A., 2003, "Investigation of thermal benefits of rooftop garden in the tropical environment." Building and Environment, 38:261-70.

[3] Kosareo L, Ries R, 2006, "Comparative environmental life cycle assessment of green roofs." Building and Environment, 42:2606-2613.

[4] Takebayashi H., Moriyama M., 2007, "Surface heat budget on green roof and high reflection roof for mitigation of urban heat island." Building and Environment, 42(8): 2971-2979. 